\title{
TURKISH USERS' ATTITUDES TOWARDS FACEBOOK ADVERTISEMENTS
}

\author{
*Kader OSKAYBAŞ \\ *Tolga DURSUN \\ *Dursun YENER \\ *Maltepe University
}

\begin{abstract}
The purpose of this paper is to determine the effects of different factors on the formation of users' attitudes towards advertisements on Facebook, the current leading social networking site. For this purpose, Pollay and Mittal's scale aimed at measuring the public opinion towards advertisements was modified and used. Data obtained from 101 participants was evaluated. The model of the survey tries to determine the existence and the nature of the relationships between societal effects and personal uses of Facebook advertisements and the attitudes of the site's users' towards those advertisements. According to the results, perceived personal usage factors of Facebook advertisements, along with certain perceived societal effects contribute to the formation of attitudes towards Facebook advertisements.
\end{abstract}

Keywords: Consumer Attitudes, Social Media, Facebook

\section{INTRODUCTION}

The end of the 20th century saw the invention of the Internet, and the way of daily life has started to change. First, getting information and communication became easier, and as a result, consumers' needs started changing, which, in turn, led to businesses starting to abandon conventional models of business and started shifting towards e-commerce.

One of the steps many businesses have taken to answer the changing consumer needs is to establish a presence on social media sites. Social media sites allow businesses and customers to interact instantaneous much like the telephone- but, the interaction most often can be viewed and, in a sense, overseen by other customers. A presence on social networking sites also allows businesses to track their customers' interests closely by letting them friend or follow the customers, and thus letting them follow what the customers like, what events the customers attend, and what the customers share about themselves.

Facebook is currently the leading social network site in the world. In Turkey, the majority of people with online access are members of the Facebook. Due to the popularity of Facebook among Turkish users, this paper focuses on the attitudes of Facebook's Turkish users' attitudes toward advertisements on Facebook.

\section{LITERATURE REVIEW AND HYPOTHESES}

\section{Social Media And Consumer Attitudes}

Weber (2007) defines social media as "The social media is the online place where people with a common interest can gather to share thoughts, comments, and opinions". According to Kaplan and Haen lein (2010) social media is "a group of Internet-based applications that build on the ideological and technological foundations of Web 2.0, and that allow the creation and exchange of user-generated content". Social media is being widely used around the globe even by the companies. Despite their volu me and sizes, they have started using social media and its tools to advertise and promote their products and their companies (Saravanaku mar and Lakshimi, 2012: 4445).

The etymological stem of the word "attitude" is the Latin "aptus", which equals to "joined, fitted" in modern English. In $17^{\text {th }}$ century, the term "attitude" was used as a technical term to denote the posture of a figure in a statue or painting. Later in the $18^{\text {th }}$ century, the meaning of the word was generalized to "a posture of the body supposed to imply some mental state". Only in the mid- $19^{\text {th }}$ century have the connotations of "settled 
Journal Of Global Strategic Management | V. 8 | N. 2 | 2014-December | isma.info | 17-25 | DOI:10.20460/JGSM.2014815638 behavior reflecting feeling or opinion" started to be attached to the word (http://www.etymonline.com/index.php?term =attitude, retrieved on $13^{\text {th }}$ of March, 2014).

Although the meaning of the term has been redefined countless times in the past century, Thurstone's definition of it as "the amount of affect or feeling for or against a stimuli" captures the widest area on its current usage. The definition of attitudes as "evaluations of a concept or object, such as an issue, person, group, brand or service that expresses a degree of favor or disfavor" is more relevant to the topic of consumer behavior. Consumers form these evaluations by integrating knowledge, meanings or beliefs about the attitude object - the entity that gets evaluated. Attitudes are both concrete and protean, in the sense that once one about an object is formed, consumers activate the said attitude from memory and incorpo rate their interpretation of new information into it, instead of forming a new attitude each time they come upon a new bit of information (Peter \& Olson, 1999). This implies that an attitude toward an object might differ in different points in time. The changes an attitude might undergo depend on three characteristics: Attitude availability, attitude accessibility and attitude strength (Arnould, Price \& Zinkhan, 2004).

Attitudes about most objects are an amalgam of numerous feelings, thoughts and experiences of both positive and negative nature. In addition, attitudes are not necessarily always verging on the extremes. Neutral evaluations are not uncommon, especially towards relatively un-important concepts that do not require high levels of involvement (Peter \& Olson, 2005).

\section{DEVELOPMENT OF HYPOTHESES}

Pollay and Mittal (1993) posit that seven effects that might be yielded by advertising and can affect formation of attitudes toward advertising. They divide those seven effects into two main categories, namely: Personal Uses and Societal Effects. The seven effects determined by Pollay and Mittal are as follows:

Personal Uses:

- Product Information: Some arguments advocating usefulness of advertising are based upon its role as a provider of information. The information obtained from advertising might increase market efficiency by more accurately matching customers' needs and producers' offerings.

- Social Role and Image: Most advertising provide lifestyle imagery, aimed at association of the product with status and prestige. Many consumers agree to pay premium prices for effectively branded products.

- Hedonic / Pleasure: The experience of looking at or remembering an advert itself can be a pleasurable.

\section{Societal Effects:}

- Good for the Economy: Arguments advocating adverts claim that advertisement can speed up the acceptance of new products by the costumers, ultimately fostering full employ ment, lower production expenses, and similar larger-scale results.

- Materialism: Critics of advertising claim that the display of countless products in an attractive manner preoccupies consumers with commercial concerns and divert them from social, political and philos ophical concerns.

- Value Corruption: Advertisements are built upon premises of values. Values portrayed and promised, critics of adverts claim, reinforce tendencies towards the "seven deadly sins" (greed, lust, gluttony, envy, sloth, pride, and anger) more than they do the "seven cardinal virtues" (prudence, temperance, justice, fortitude, faith, hope, and charity).

- Falsity / No Sense: Advertising in general has been accused of being purposefully misleading or not fully informing. In such cases, the personal usefulness of adverts as information sources diminishes. Furthermore, such ads can damage communities they are served to by promoting half-truths as truths.

Global Attitudes: Specific beliefs listed above are claimed to be in accordance with more generalized attitudes that exist at another cognitive abstraction (Pollay \& Mittal, 1993). 
All the statements used were modified and reworded for measure ment of attitude formation toward Facebook advertisements.

H1: Evaluation of Product Information factor influences Attitude toward Facebook advertisements positively.

H2: Evaluation of Social Role and Image factor influences Attitude toward Facebook advertisements positively.

H3: Evaluation of"Hedonic / Pleasure" factor influences Attitude toward Facebook advertis ements positively.

H4: Evaluation of "Good for the Economy” factor influences Attitude toward Facebook advertisements positively.

H5: Evaluation of “Falsity / No Sense” factor influences Attitude toward Facebook advertis ements negatively.

H6: Evaluation of "Corrupts Values" factor influences Attitude toward Facebook advertis ements negatively.

H7: Evaluation of "Materialis m" factor influences Attitude toward Facebook advertisements negatively.

\section{METHODOLOGY}

\section{Research Goal}

The purpose of this survey is to determine the effects of different factors on the formation of users' attitudes towards advertisements on Facebook, the current leading social networking site. For this purpose, Pollay and Mittal's scale aimed at measuring the public opinion towards advertisements was modified and used. In addition to the factors adapted from Pollay and Mittal's model, the existence of relationships between demographic characteristics of the participants and their attitudes towards the Facebook advertisements was also tried to be determined.

\section{Sample and Data Collection}

Data obtained in this survey was computerized in Microsoft Excel and SPSS 18.0 programs. In this study, 7 questions about participants' demographic characteristics and 39 statements each were compiled into a survey and the resulting survey was published online to determine participants' attitudes towards Facebook advertisements in accordance with seven attribute model adapted from Pollay and Mittal. Participants were asked to state to what extent they agree with the statements on a scale of 1 to 5. Agreement degrees for 39 attribute statements were designed as 1-Strongly disagree, 2-Disagree, 3-Neutral, 4-Agree, 5-Strongly Agree. Each attribute assessment was then scored on the scale of 100 to calculate importance weights of each quality dimension.

\section{Analyses and Results}

Reliability is an important concept for research findings. Gegez (2010) explained that reliability indicates whether or not the same results are going to be obtained when a research is repeated and whether respondents would give same answers in case of no change of their state. For reliability analysis of this survey Cronbach's alpha model was used. Cronbach's alpha model, in the words of George and Mallery (2001, p.209), is an indicator of to what extent all the items in a scale can successfully measure any dimension.

Reliability analysis comes to the front to gauge inter-closeness degree of questions when calculation is made by summating the values of answers to certain numbers of questions. This is also called as internal consistency. Most preferred method for reliability analysis is Cronbach Alpha model. This model calculates the coefficient alpha. Coefficient is obtained by comparing overall variations of quest ion to general variation in a scale. Alpha is a standard change mean and varies between 0 and 1. According to Nakip's explanation; in social research, an alpha value of 0,70 is accepted as 'adequate' for reliability (Nakip, 2013).

\section{Demographic Features}

$46 \%$ of total participants were female and $53 \%$ were male, while $18.8 \%$ of the participants were married, $80.2 \%$ were single, and $1 \%$ were divorced or widowed. 24 to 29 age bracket was the largest group among the participants with $56.4 \%$, followed by 18 to 23 groups with $30.7 \%, 30$ to 34 groups with $8.9 \%$, and 35 to 39 groups with only $4 \%$. 
Table 1: Demographic Characteristics of the Participants

\begin{tabular}{|c|c|c|c|c|c|}
\hline Gender & $\mathbf{N}$ & $\%$ & Income & $\mathbf{N}$ & $\%$ \\
\hline Female & 47 & 46 & $<1000 \mathrm{TL}$ & 32 & 31.7 \\
\hline Male & 54 & 53 & $1001-1500 \mathrm{TL}$ & 10 & 9.9 \\
\hline Age & $\mathbf{N}$ & $\%$ & $1501-2000 \mathrm{TL}$ & 18 & 17.8 \\
\hline $18-23$ & 31 & 30.7 & $2001-2500 \mathrm{TL}$ & 10 & 9.9 \\
\hline $24-29$ & 57 & 56.4 & $2501-5000 \mathrm{TL}$ & 22 & 21.8 \\
\hline $30-34$ & 9 & 8.9 & $5001+\mathrm{TL}$ & 5 & 5.0 \\
\hline $35-39$ & 4 & 4.0 & Occupation & $\mathbf{N}$ & $\%$ \\
\hline Marital Status & $\mathbf{N}$ & $\%$ & Academician & 5 & 5.0 \\
\hline Single & 81 & 80.2 & Engineer & 2 & 2.0 \\
\hline Married & 19 & 18.8 & Lawyer & 3 & 3.0 \\
\hline Divorced/Widowed & 1 & 1.0 & Other & 3 & 3.0 \\
\hline Education & $\mathbf{N}$ & $\%$ & Private Sector & 28 & 27.7 \\
\hline Postgraduate & 27 & 26.7 & Public Employee & 2 & 2.0 \\
\hline Undergraduate & 63 & 62.4 & Self-Employed & 10 & 9.9 \\
\hline Associate's & 2 & 2.0 & Student & 48 & 47.5 \\
\hline High School & 8 & 7.9 & Have Children & $\mathbf{N}$ & $\%$ \\
\hline \multirow[t]{2}{*}{ Literate } & 1 & 1.0 & Yes & 14 & 13.9 \\
\hline & & & No & 87 & 86.1 \\
\hline
\end{tabular}

The monthly personal income of $31.7 \%$ of the participants was less than 1000TL. This group was followed by $21.8 \%$ of the participants with an income between 2501 and $5000 \mathrm{TL}, 17.8 \%$ between 1501 and 2000TL, 9.9\% with both between 1001 and 1501TL, and between 2001 and 2500TL, and, the s mallest group, 5\% with more than 5001TL of monthly personal income.

As to the occupation of the participants: With $47.5 \%$, almost half of the participants were students, while $27.7 \%$ were employed in private sector. $9 \%$ of the participants were self-employed. Academicians, lawyers, engineers, public sector employees and those who were working in branches other than the options given in the survey made up 5\%,2\%,3\%,2\% and 3\% of the participants, respectively.

$62.4 \%$ of the participants either had or were working towards an undergraduate degree. $26.7 \%$ of the participants were post-graduates. Those of the participants who had an associate's degree made up $2 \%$ of the total number of participants. High school graduates made up $7.9 \%$ percent of the participants, while only $1 \%$ of the participants' education level was literate - meaning they have not completed any high school level education.

\section{Evaluation of Participants' Answers}

"Global attitudes" factor consists of 4 variables in the survey. Factor weight of each variable can be found on the 3rd colu mn of the table. Explained variation percentage is $\% 66,52$, which means that the aforementioned four variables account for \%66.52 of the "global attitudes" factor. KMO test, performed to ascertain whether the sample was adequate for factor analysis, needed to be 0,7 or higher. For "Global Attitudes" factor, the KMO test result was adequate. Bartlett test is used to ascertain whether the variables could be used for factor analysis. Values lower than 0,05 mean that the variable can be used for factor analysis.

"Product Information" factor consists of 3 variables in the survey. Explained variation percentage for this factor was \% 67,01. KMO test resulted in a value of 0,657 for this factor. Bartlett value for this factor was also below 0,05 .

"Social Role and Image Formation" factor consists of 3 variables in the survey. Explained variation percentage for this factor was \%64,74. KMO test resulted in a value of 0,658 for this factor. Bartlett value for this factor was also below 0,05 . 
"Hedonic / Pleasure" factor consists of 3 variables in the survey. Explained variation percentage for this factor was \% 65,98. KMO test resulted in a value of 0,652 for this factor. Bartlett value for this factor was also below 0,05 .

"Good for the Economy" factor consists of 5 variables in the survey. Explained variation percentage for this factor was \%67,01. KMO test resulted in a value of 0,721 for this factor. Bartlett value for this factor was also below 0,05 .

"Materialism" factor consists of 4 variables in the survey. Explained variation percentage for this factor was $\% 57,6$. KMO test resulted in a value of 0,694 for this factor. Bartlett value for this factor was also below 0,05.

For "Falsity/No Sense" and "Value Corruption" factors, the KMO values were not adequate, and thus these factors have been omitted from the analysis.

Table 2: Results of the Reliability Tests

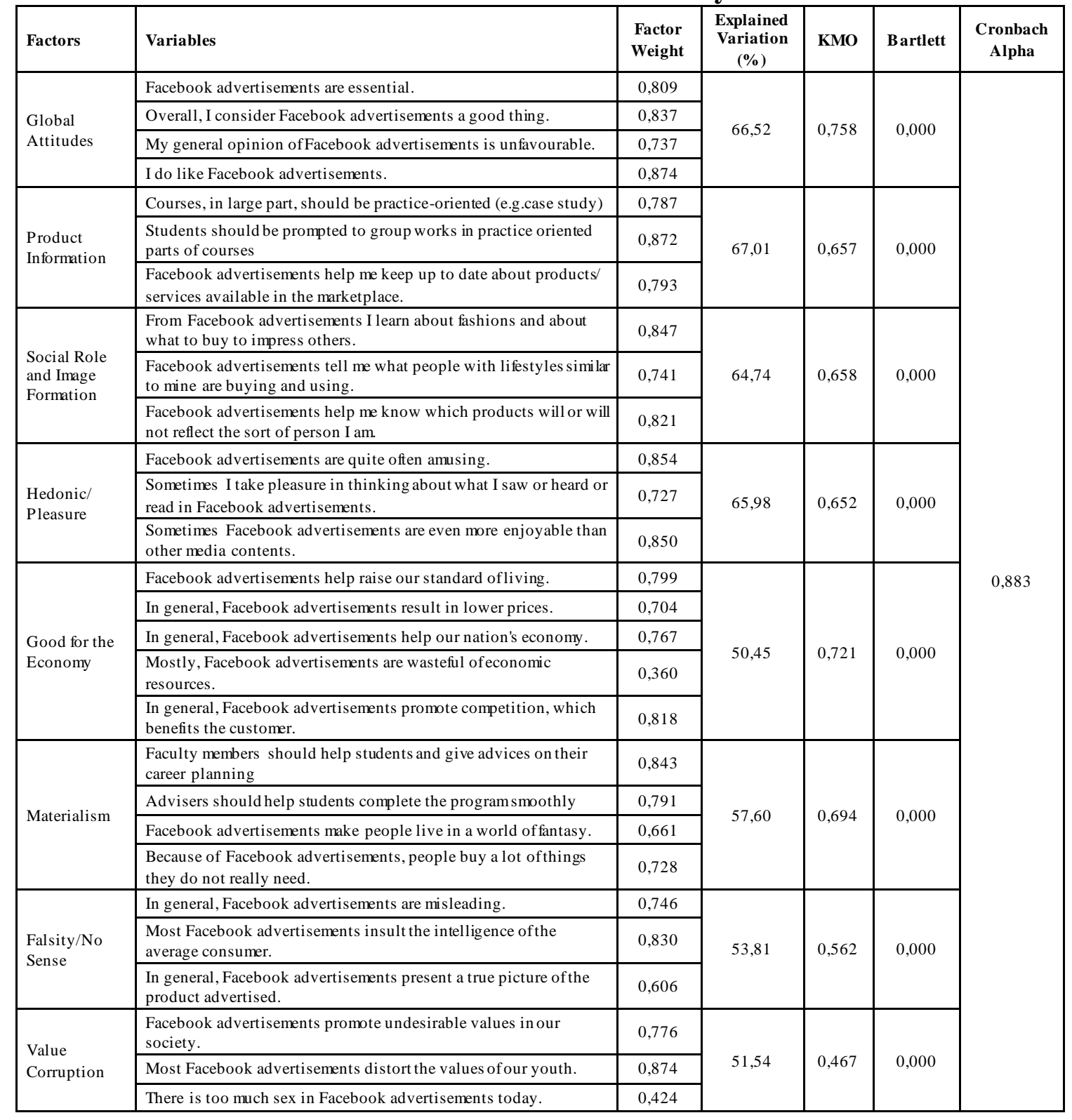

Analysis also showed in-group differences in four demographic characteristics. Those characteristics are listed below: 
- Education

- Age

- Marital Status

- Children

Table 3: Comparison of Effects Measured by Education Level

\begin{tabular}{|l|l|c|c|c|c|c|}
\hline & & Sum of Squares & df & Mean Square & F & Sig. \\
\hline \multirow{5}{*}{ Global Attitudes } & Between Groups & 3,883 & 4 & 0,971 & 3,044 & 0,021 \\
\cline { 2 - 7 } & Within Groups & 30,617 & 96 & 0,319 & & \\
\cline { 2 - 7 } & Total & 34,500 & 100 & & & \\
\hline \multirow{5}{*}{ Product Information } & Between Groups & 10,771 & 4 & 2,693 & 3,27 & 0,015 \\
\cline { 2 - 7 } & Within Groups & 79,066 & 96 & 0,824 & & \\
\cline { 2 - 7 } & Total & 89,837 & 100 & & & \\
\hline \multirow{5}{*}{ Good for the Economy } & Between Groups & 6,330 & 4 & 1,582 & 2,575 & 0,042 \\
\cline { 2 - 7 } & Within Groups & 58,997 & 96 & 0,615 & & \\
\cline { 2 - 7 } & Total & 65,327 & 100 & & & \\
\hline
\end{tabular}

Deduced from the data is that for the factors included in the table above, participants' education level did show some statistical difference, but, since a post-hoc test was not performed, the exact differences between educational status is not clear.

Table 4: Comparison of "Hedonic / Pleasure" Effect by Age

\begin{tabular}{|l|l|c|c|c|c|c|}
\hline & & Sum of Squares & df & Mean Square & F & Sig. \\
\hline \multirow{5}{*}{ Hedonic/Pleasure } & Between Groups & 5,726 & 3 & 1,909 & 3,106 & 0,03 \\
\cline { 2 - 8 } & Within Groups & 59,601 & 97 & 0,614 & & \\
\cline { 2 - 8 } & Total & 65,327 & 100 & & & \\
\hline
\end{tabular}

Hedonic/Pleasure factor shows fluctuations relative to the age of participants. When mean values are analyzed, it can be seen that the highest Hedonic / Pleasure score belongs to the 35-39 age group. It was also seen that Hedonic / Pleasure score increased as the age of the participants did.

Table 5: Comparis on of Effects Measured by Marital Status

\begin{tabular}{|c|c|c|c|c|c|c|}
\hline & & Sum of Squares & df & Mean Square & $\mathrm{F}$ & Sig. \\
\hline \multirow[t]{3}{*}{ Global Attitudes } & Between Groups & 4,395 & 2 & 2,197 & 7,153 & 0,001 \\
\hline & Within Groups & 30,105 & 98 & 0,307 & & \\
\hline & Total & 34,500 & 100 & & & \\
\hline \multirow[t]{3}{*}{ Product Information } & Between Groups & 7,553 & 2 & 3,777 & 4,498 & 0,014 \\
\hline & Within Groups & 82,284 & 98 & 0,84 & & \\
\hline & Total & 89,837 & 100 & & & \\
\hline \multirow[t]{3}{*}{ Hedonic/Pleasure } & Between Groups & 5,968 & 2 & 2,984 & 4,926 & 0,009 \\
\hline & Within Groups & 59,359 & 98 & 0,606 & & \\
\hline & Total & 65,327 & 100 & & & \\
\hline
\end{tabular}

As it was the case with the education level, participants' marital status did show some statistical difference for the factors listed in the table above, but, since a post-hoc test was not performed, the exact diffe rences between marital status is not clear. 
Journal Of Global Strategic Management | V. 8 | N. 2 | 2014-December | isma.info | 17-25 | DOI:10.20460/JGSM.2014815638

Table 6: Comparison of "Hedonic / Pleasure" Effect by Having Children

\begin{tabular}{|c|c|c|c|c|c|c|c|}
\hline \multicolumn{8}{|c|}{ Group Statistics } \\
\hline & Children & \multicolumn{2}{|l|}{$\mathrm{N}$} & Mean & Std. Deviation & \multicolumn{2}{|c|}{ Std. Error Mean } \\
\hline \multirow[t]{2}{*}{ Hedonic/Pleasure } & Yes & \multicolumn{2}{|l|}{14} & 2,50 & 0,994 & \multicolumn{2}{|c|}{0,266} \\
\hline & No & \multicolumn{2}{|l|}{87} & 1,77 & 0,732 & \multicolumn{2}{|c|}{0,078} \\
\hline \multicolumn{8}{|c|}{ Independent Samples Test } \\
\hline & & & \multicolumn{2}{|c|}{$\begin{array}{c}\text { Levene's Test for Equality } \\
\text { of Variances }\end{array}$} & \multicolumn{3}{|c|}{ t-test for Equality of Means } \\
\hline & & & $\mathrm{F}$ & Sig. & $\mathrm{t}$ & $\mathrm{Df}$ & Sig. (2-tailed) \\
\hline \multirow[t]{2}{*}{ Hedonic / Pleasure } & \multicolumn{2}{|c|}{ Equal variances assumed } & 2,165 & 0,144 & 3,286 & 99 & 0,001 \\
\hline & \multicolumn{2}{|c|}{$\begin{array}{c}\text { Equal variances not } \\
\text { assumed }\end{array}$} & & & 2,636 & 15,352 & 0,018 \\
\hline
\end{tabular}

When the relationship between participants' having children or not and the "hedonic / pleasure" factor was viewed, it was seen that the participants with children had a higher value across the "hedonic / pleasure" factor than those who did not have children.

Table 7: Correlation Analysis

\begin{tabular}{|c|c|c|c|c|c|c|c|c|}
\hline & & 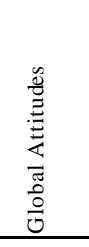 & 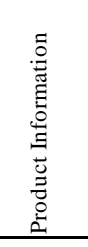 & 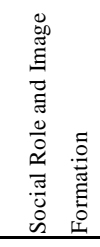 & 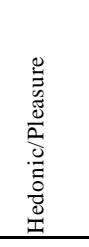 & 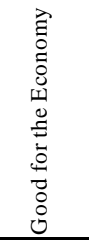 & 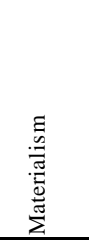 & 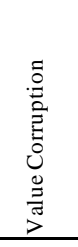 \\
\hline \multirow[t]{3}{*}{ Global Attitudes } & Pearson Cor. & 1 &, $626 * *$ &, $435^{* *}$ &, $592 * *$ &, $582 * *$ &, $201 *$ & 0,123 \\
\hline & Sig. (2-tailed) & & 0 & 0 & 0 & 0 & 0,044 & 0,222 \\
\hline & $\mathrm{N}$ & 101 & 101 & 101 & 101 & 101 & 101 & 101 \\
\hline \multirow[t]{3}{*}{ Product Information } & Pearson Cor. &, $626 * *$ & 1 &, $647^{* *}$ &, $566 * *$ &, $574 * *$ & 0,177 & 0,192 \\
\hline & Sig. (2-tailed) & 0 & & 0 & 0 & 0 & 0,077 & 0,055 \\
\hline & $\mathrm{N}$ & 101 & 101 & 101 & 101 & 101 & 101 & 101 \\
\hline \multirow{3}{*}{$\begin{array}{l}\text { Social Role and Image } \\
\text { Formation }\end{array}$} & Pearson Cor. &, $435 * *$ &, $647 * *$ & 1 &, $525 * *$ &, $553 * *$ &, $229 *$ & 0,157 \\
\hline & Sig. (2-tailed) & 0 & 0 & & 0 & 0 & 0,021 & 0,117 \\
\hline & $\mathrm{N}$ & 101 & 101 & 101 & 101 & 101 & 101 & 101 \\
\hline \multirow[t]{3}{*}{ Hedonic / Pleasure } & Pearson Cor. &, $592 * *$ &, $566 * *$ &, $525 * *$ & 1 &, $631 * *$ & 0,145 & 0,126 \\
\hline & Sig. (2-tailed) & 0 & 0 & 0 & & 0 & 0,149 & 0,209 \\
\hline & $\mathrm{N}$ & 101 & 101 & 101 & 101 & 101 & 101 & 101 \\
\hline \multirow[t]{3}{*}{ Good for the Economy } & Pearson Cor. &, $582 * *$ &, $574 * *$ &, $553 * *$ &, $631 * *$ & 1 &, $489 * *$ &, $439 * *$ \\
\hline & Sig. (2-tailed) & 0 & 0 & 0 & 0 & & 0 & 0 \\
\hline & $\mathrm{N}$ & 101 & 101 & 101 & 101 & 101 & 101 & 101 \\
\hline \multirow[t]{3}{*}{ Materialism } & Pearson Cor. &, $201 *$ & 0,177 &, $229 *$ & 0,145 &, $489 * *$ & 1 &, $530 * *$ \\
\hline & Sig. (2-tailed) & 0,044 & 0,077 & 0,021 & 0,149 & 0 & & 0 \\
\hline & $\mathrm{N}$ & 101 & 101 & 101 & 101 & 101 & 101 & 101 \\
\hline \multirow[t]{3}{*}{ Value Corruption } & Pearson Cor. & 0,123 & 0,192 & 0,157 & 0,126 &, $439 * *$ &, $530 * *$ & 1 \\
\hline & Sig. (2-tailed) & 0,222 & 0,055 & 0,117 & 0,209 & 0 & 0 & \\
\hline & $\mathrm{N}$ & 101 & 101 & 101 & 101 & 101 & 101 & 101 \\
\hline
\end{tabular}

Between "Global Attitudes" and "Product Information" lies a significance value of 0, which indicates that there is a significant relationship between them. Pearson correlation value is 0,626 , which indicates that the relationship between these two factors is a positive one. According to these values, it can be said that Hypothesis 1 can be accepted. 
Journal Of Global Strategic Management | V. 8 | N. 2 | 2014-December | isma.info | 17-25 | DOI:10.20460/JGSM.2014815638 Between "Global Attitudes" and "Social Role and Image Formation" lies a significance value of 0, which indicates that there is a significant relationship between them. Pearson correlation value is 0,435 , which indicates that the relationship between these two factors is a positive one. According to these values, it can be said that Hypothes is 2 can be accepted.

Between "Global Attitudes" and "Hedonic / Pleasure" lies a significance value of 0, which indicates that there is a significant relationship between them. Pearson correlation value is 0,592 , which indicates that the relationship between these two factors is a positive one. According to these values, it can be said that Hypothesis 3 can be accepted.

Between "Global Attitudes" and "Good for the Economy" lies a significance value of 0, which indicates that there is a significant relationship between them. Pearson correlation value is 0,582 , which indicates that the relationship between these two factors is a positive one. According to these values, it can be said that Hypothesis 4 can be accepted.

Between "Global Attitudes" and "Materialis m" lies a significance value of 0,044, which indicates that there is a significant relationship between them. Pearson correlation value is 0,123 , which indicates that the relationship between these two factors is a positive one. According to these values, it can be said that Hypothesis 7 can be accepted.

Between "Global Attitudes" and "Value Corruption" lies a significance value of 0,222, which indicates that there is a significant relationship between them. Pearson correlation value is 0,123 , which indicates that the relationship between these two factors is a positive one. According to these values, it can be said that Hypothesis 6 can be accepted. Analysis returned inconclusive results on Hypotheses 5.

\section{CONCLUSION}

With the advent of Internet technologies, many businesses started to spill their functions over to the cyber world to provide more ease and speed to their customers. As the social media sites started to become widely accepted and used, companies started using those sites to strengthen and improve their relationships with the customers, as well as to reach new customers. As the companies started establishing themselves on social networking sites and become more easily reachable, advertisements for businesses started finding their way into these sites too.

To determine the attitude of Turkish Facebook users' attitude towards advertisements on Facebook, a survey was prepared and 101 answer sets were collected. Analysis of the data collected indicates that there is a positive relationship between participants' evaluation of the "Product Information", "Social Role and Image Formation", "Hedonic / Pleasure", "Good for the Economy", "Materialism", and "Value Corruption" factors and participants' global attitudes towards Facebook advertisements. The effect of "Falsity / No Sense" factor on Facebook advertisements could not be determined due to these factors' variables turning out to be unreliable.

In light of these results, it can be said that companies considering foraying into the social media arena should put the focus in the advertisements they are going to use in Facebook on the adverts' being informing and picturing the social image it is trying to foster as clearly as possible. The advertisement used should be prepared in accordance with the culture of the target base it will be used for, for the results show -just like the old-media ads- Facebook advertisements too can be deemed as corrupting the values of the population they are exposed to. Undertones that might foster materialistic tendencies will also meet resistance from the customers, and have a negative effect on customers' general attitude towards the advertis ement.

Further research with a larger sample might shed more light between users' evaluation of the effects included in the model and their overall attitude towards Facebook advertisements. In addition, research about users' attitude towards advertisements on social media outlets other than Facebook might be used to determine different attitudes and cross-site trends. 


\section{REFERENCES}

Arnold, E., Price, L., \& Zinkhan, G. (2004). Consumers. New York: McGraw-Hill/Irwin.

Gegez, E. (2007), Pazarlama Araştırmaları, Second Edition. Istanbul: Beta Publishing Company.

Gibson, B., (2007). Enabling an Accessible Web 2.0. 16th International World Wide Web Conference. May 07-08, 2007, Banff, Canada.

Kaplan, A. M., \& Haenlein, M. (2010). Users of the world, unite! The challenges and opportunities of Social Media. Business horizons, 53(1), 59-68.

Kinsella, S., A. Budura, G. Skobeltsyn, S. Miche, J. Breslin, K. Aberer, (2008). From Web 1.0 to Web 2.0 and Back -How did your Grandma Use to Tag? Tenth 102 International Workshop on Web Information and Data Management (WIDM’08).

Leiner at al. (2009). A Brief History of the Internet. ACM SIGCOMM Computer Communication Review, Volume 39, Number 5, October 2009.

O'Reilly, T., \& Battelle, J. (2009). Web squared: Web 2.0 five years on (Vol. 20, No. 1). O'Reilly Media.

Peter, J. P., Olson, J. C., \& Grunert, K. G. (1999). Consumer behavior and marketing strategy (pp. 329-48). London: McGraw-Hill.

Pollay, R. W., Mittal B., (1993). Here's the beef: factors, determinants and segments in consumer criticism of advertising. Journal of Marketing, 57(3), 99-114.

Saravanakumar M, SuganthaLakshmi T.(2012), Social Media, http://www.lifesciencesite.com

Smith, T. (2009). The social media revolution. International journal of market research, 51(4), 559-561.

Nakip, Mahir (2013) Pazarlamada Araştırma Teknikleri, Ankara Seçkin Yayınc1lık

Ety mology Dictionary, http://www.ety monline.co m/index.php?term=attitude, retrieved on 13th of March, 2014.

Weber, L. (2007), Marketing to the Social Web: How Digital Customer Communities Build Your Business. New Jersey: John Wiley and Sons Inc.

Zhang, Z., Cheung, K. H., \& Townsend, J. P. (2009). Bringing Web 2.0 to bioinformatics. Briefings in bioinformatics, 10(1), 1-10. 